\title{
Student self-confidence with clinical nursing competencies in a high-dose simulation clinical teaching model
}

\author{
Donna E. McCabe , Mattia J. Gilmartin, Lloyd A. Goldsamt \\ New York University College of Nursing, New York, United States
}

Received: December 7, 2015

DOI: $10.5430 /$ jnep.v6n8p52

\author{
Accepted: February 25, 2016 \\ Online Published: March 30, 2016 \\ URL: http://dx.doi.org/10.5430/jnep.v6n8p52
}

\begin{abstract}
Objective: This paper describes undergraduate nursing students' assessment of confidence in clinical practice within a model that uses a "high-dose" of clinical simulation to replace $50 \%$ of the traditional clinical experience hours in an upper division bachelor's degree program. We assessed changes in self-reported confidence between the middle and end of a two-year nursing curriculum.

Design: Longitudinal design. We surveyed undergraduate nursing students to assess their perceived self-confidence in carrying out eight core competencies associated with generalist nursing practice with the Assessment of Nursing Education Scale (Robert Wood Johnson Foundation, 2009) at the mid-point (semester 2) and end of program (semester 4).

Methods: Data were analyzed Generalized Linear models. To account for changes over time, we included program track (traditional BSN or 15-month accelerated second degree program) and gender (male/female) as co-variates in the models.

Results: One hundred and twenty-two students completed the ANE at the two time points. Results for analysis of student confidence over time showed significant improvement on each of the eight domains of generalist nursing practice. There was no significant effect of gender or program type on student's perceived self-confidence.

Conclusions: Overall significant improvement in students' self-assessed confidence from program mid-point to end-point lends support to the efficacy of a clinical teaching model that uses a high dose of simulation to substitute for traditional clinical hours.
\end{abstract}

Key Words: Simulation, Nursing education, Self-confidence

\section{INTRODUCTION}

Nurse educators strive to improve the education of students so that new workforce entrants have the knowledge, skills, and abilities to provide care that is effective, efficient, and safe. The extensive knowledge and competencies students need to develop for entry into practice are often compounded by issues related to limited clinical placement sites and a nursing faculty shortage, affecting the clinical experiences of students in their nursing programs. Over the years, different models of teaching undergraduate nursing students have emerged with the aim of mitigating these challenges while providing high quality education to future nurse professionals.

The use of simulation has become a tool for innovating clinical teaching models for many types of healthcare professionals. While the concept of "simulation" is not new, its

\footnotetext{
*Correspondence: Donna E. McCabe; Email: donna.mccabe@nyu.edu; Address: New York University College of Nursing, 433 First Avenue, New York, United States.
} 
recent emergence in nursing education has been revolutionary. There are many different ways and amounts in which simulation is used across undergraduate programs in the United States. ${ }^{[1]}$ Evaluating the effectiveness of new clinical teaching models for clinical simulation within baccalaureate curriculum remains a challenge. Few studies have examined student development of knowledge, competencies for practice, and student perceived confidence in their clinical practice abilities in a nursing program using a high dose of clinical simulation.

Our college operates in a market where multiple undergraduate nursing programs compete for appropriate clinical placement sites. This, in combination with the escalating nurse faculty shortage, provided the major impetus for developing the high-dose clinical teaching model which substitutes $50 \%$ of the teaching hours in the core medical-surgical courses with high-fidelity simulation. ${ }^{[2]}$ This paper describes undergraduate nursing students' assessment of confidence in clinical practice within this model that uses a "high-dose" of clinical simulation to replace the traditional clinical experience.

\subsection{Clinical teaching model}

Faced with the challenges of increased student demand, limited clinical placement sites, and a faculty shortage, our nursing program sought to develop an innovative clinical teaching model. Traditional clinical practice in the pre-licensure nursing program was substituted with clinical simulations in the core medical-surgical nursing courses for $50 \%$ of the clinical experiences. Simulation was also integrated into the specialty nursing courses at different "doses", all of which were less than $50 \%$ of total clinical experiences. The majority of the simulation is high-fidelity clinical simulations that are appropriately leveled for the course and become increasing complex in the latter parts of the curriculum. A high degree of control in the design of the scenarios, which is managed by a group of core faculty, ensures that key elements are included, highly prevalent conditions are represented, and course and program outcomes are met.

The clinical simulations and traditional clinical experiences are related to didactic courses and scheduled on alternate weeks to facilitate integration of the learning experiences. The student group may be in a clinical simulation week one of the semester, traditional clinical on week two, and back to clinical simulation for week three, and so forth for the duration of the semester. These days are referred to as "oncampus clinical" and "off-campus clinical" to emphasize that both experiences serve as clinical experiences. There is a course coordinator who is responsible for oversight of the entire course and separate instructors for the on-campus and

Published by Sciedu Press off-campus clinical experiences. The design of the course with weekly didactic time and either on-campus clinical or off-campus clinical requires good organization and communication among all participating faculty. A full description of the clinical teaching model is reported in Richardson et al. ${ }^{[2]}$

\subsection{Literature review}

\subsubsection{Simulation}

The use of simulation in nursing education has existed for more than 40 years in different forms, from learning bandaging on static models to complex patient scenarios using high-fidelity mannequins. ${ }^{[3-5]}$ Simulation has gained credibility as an effective teaching technique for undergraduate nursing students, and there is evidence to support the increase of knowledge, skills, and critical thinking, and the ability to recognize a deteriorating patient using clinical simulation. ${ }^{[6-8]}$ Studies also indicate that with simulation students have increased critical thinking skills. ${ }^{[9-11]}$

Despite common use and evidence to support its effectiveness, the use of simulation in health professions education remains controversial. A meta-analysis conducted by Spence Laschinger ${ }^{[12]}$ examined simulation among nursing, medicine, and rehabilitation therapy pre-licensure students and found that learners enjoy simulation and that it made learning easier. The analysis of the research found that there were discrepancies in how learning skills in the simulation environment transferred into practice, and concluded that simulation is a valuable adjunct to clinical practice, but not a replacement for everyday practice. ${ }^{[12]}$

The use of simulation in education has gained in popularity and as of 2011 had been included in 917 nursing programs across the United States. The amount of simulation that should be used in pre-licensure education, and if and to what extent it replaces traditional clinical learning experiences, have been debated. Hayden and colleagues ${ }^{[1]}$ reported that nursing programs were asking permission of the National Council of State Boards of Nursing (NCSBN) to replace traditional clinical practice with simulation to mitigate some of the challenges associated with faculty shortages and lack of clinical placements sites. These requests served as the impetus for the NCSBN National Simulation Study, which explored the replacement of traditional clinical hours with simulation.

The NCSBN study was a longitudinal, randomized control trial replacing traditional clinical hours with high quality simulation. This robust study examined outcomes of nursing programs that replaced traditional clinical hours with less than $10 \%$ simulation, $25 \%$ simulation, or $50 \%$ simulation. The study findings indicated that substituting high-quality 
simulation experiences for up to half of traditional clinical hours resulted in comparable end-of-program educational outcomes, with new graduates prepared for entry into practice. ${ }^{[1]}$ This evidence gives support to the integration of high quality simulation into undergraduate nursing programs. Barriers to integration remain at the state level, with currently eight states and three territories prescribing minimum required clinical hours for RN programs. Eight states do not allow simulation to be used as substitute for clinical hours. ${ }^{[1]}$

\subsubsection{Student self-assessment/self-confidence}

Confidence in one's ability to effectively carry out a task within a specific situation is an important aspect of nursing practice and a focus of nursing education. Previous research has shown that individuals' self-confidence is a predictor of their ability to perform effectively in new situations. ${ }^{[13-15]}$ Moreover, a person's belief in his or her self-confidence varies according to the 1 ) difficulty of the task, 2) certainty in performing a task at a given level of difficulty, and 3) extent to which the difficulty of the task generalizes across situations. ${ }^{[14]}$ Because nursing is a contextually situated practice, an individual's competence in any given clinical situation is derived from building a repertoire of experiences to inform clinical decision making. ${ }^{[16]}$

There is a growing body of evidence to support the connection between improved self-confidence and implied critical thinking via the use of simulation among pre-licensure nursing students. A review of the literature published by Leigh ${ }^{[17]}$ noted that in general, there was a correlation between the use of simulation and perceived self-confidence. Studies have evaluated single scenarios involving skills such as inserting peripheral lines ${ }^{[18]}$ and managing a deteriorating patient ${ }^{[19]}$ that can improve student self-confidence. Other studies have examined self-confidence over courses and semesters. Blum and colleagues ${ }^{[20]}$ conducted a study examining 66 students that hypothesized that students who received simulation as a primary method for learning skills and assessments would report greater self-confidence and clinical competence. They found there was no difference between the simulation and traditional models. Given our current knowledge of successful outcomes in teaching models that use simulation as a substitute for up to half of traditional clinical hours, it is important to examine how students perceive this type of education model.

\section{METHOD}

\subsection{Design}

The data presented here were collected as part of a larger study ${ }^{[2,21]}$ in which students were surveyed at three time points within the two-year (four semester) baccalaureate curriculum with a $50 \%$ simulation clinical teaching model. An independent evaluation team were responsible for data collection and analysis. Baseline data were collected during the first three weeks of the first semester of the nursing program. Mid-program data were collected at the end of the second semester, and end-program data were collected at the conclusion of the final semester of the program. Data were collected over a two-year period, and the study design allowed for all enrolled students to be surveyed in each of the semesters in which data were collected in the fall of 2009 through fall of 2011. Surveys were distributed during student class time by the independent evaluation team without faculty present. Student participation was voluntary throughout the study. This resulted in a small number of students who completed data collection at more than one point, and thus could be compared over time, and a larger number of individual students at each individual time point.

\subsection{Setting}

The setting for this study was a large, urban, researchintensive university located in the Northeast. The Institutional Review Board at the ABC University approved the study.

\subsection{Instruments}

Students provided demographic information, which was collected at the first data collection point only, and the Student Self-Assessment of Breadth of Nursing Education (ANE), collected at mid- and end-program. The ANE was developed for the Robert Wood Johnson Foundation's Evaluating Innovations in Nursing Education (EIN) National Program. ${ }^{[22]}$ The ANE is a global measure of generalist nursing practice used to assess the breadth of the educational content. Based on Bandura's ${ }^{[23]}$ assessment of self-efficacy, the 43item ANE measures eight domains of generalist nursing practice set forth by the American Association of Colleges of Nursing, ${ }^{[24]}$ National League for Nursing, ${ }^{[25]}$ and National Council of State Boards of Nursing. [26]

The eight practice competencies in the ANE are: 1) Clinical Prevention and Population Health (CPPH), 3 items; 2) Evidence-Based Practice (EBP), 6 items; 3) Generalist Nursing Practice (GNP), 12 items; 4) Healthcare Policy, Finance, Regulation (HCPFR), 4 items; 5) Information Management and Application of Patient Technology (IMAPCT), 4 items; 6) Inter-professional Communication and Collaboration (IPCC), 4 items; 7) Organization and Systems Leadership for Quality and Safety (OSLQS), 7 items; and, 8) Professionalism and Professional Values (PPV), 3 items. ${ }^{[22]}$

Following Bandura, respondents are asked to rate their confidence with performing the 43 tasks associated with generalist nursing practice on the day that the survey is administered. 
Respondents rate their confidence on a seven-point Likert scale $(1=$ not at all confident to $7=$ extremely confident $)$. For example, a sample item from the Generalist Nursing Practice domain is: "I can recognize changes in a patient's condition necessitating intervention."

\subsection{Procedure}

Paper copies of the survey were administered in the classroom by the independent evaluation team. A written informed consent was included as the cover sheet of the survey, and students were asked to include their names on the survey form for the purpose of matching data from different time points only (names were converted to identification numbers and matched across time points).

\subsection{Analysis}

Data were analyzed using SPSS. ${ }^{[27]}$ Separate data files were maintained for each time point, and these files were merged for the analyses described below, matching cases on the numbers assigned to each student. We used repeated measures, Generalized Linear Modeling to assess changes from midto end-program in students' self confidence in carrying out the clinical competencies associated with eight domains of generalist nursing practice. We included program track (traditional BSN or 15-month accelerated second degree program) and gender (male/female) as co-variates in the models.

Table 1. Respondent Demographics

\begin{tabular}{ll}
\hline $\mathbf{N}=\mathbf{1 2 7}$ respondents & \\
\hline Gender & 114 females (89.7\%); 13 males (10\%) \\
Age & 20-50 years; 25.88 mean age; \\
Race & (S.D. $=5.57)$ \\
$\quad$ Caucasian & $79(61.2 \%)$ \\
Asian & $30(24 \%)$ \\
African-American/Black & $9(7.0 \%)$ \\
$\quad$ Mixed Race & $5(3.9 \%)$ \\
Not identified & $3(2.3 \%)$ \\
$\quad$ Native American & $1(0.8 \%)$ \\
\hline
\end{tabular}

\section{RESULTS}

The 127 students completing the ANE at the program mid and end points were predominately female (89.1\%), Caucasian (61.2\%) and averaged 25.88 years of age (range 20-50 years, S.D. 5.57). Eighty percent of the respondents were enrolled in the accelerated second degree program. Respondent's demographic characteristics are reported in Table 1. The students in our sample are racially and ethnically diverse and mirror the changing demographic characteristics of the population of undergraduate nursing students in the U.S. According to American Association Colleges of Nursing (AACN) in 2012, the year that these data were collected, $28 \%$ of students enrolled in bachelor's degree programs rep- resent minority groups; of these $11 \%$ of students are AfricanAmerican/Black; $8 \%$ are Hispanic, $8 \%$ are Asian or Pacific Islander and $1.8 \%$ are multiracial. ${ }^{[28]}$

The ANE scale reliabilities for the eight practice competencies associated with generalist nursing practice in our sample are: 1) Clinical Prevention and Population Health (CPPH), $\alpha=.60 ; 2)$ Evidence-Based Practice (EBP), $\alpha=.79 ; 3$ ) Generalist Nursing Practice (GNP), $\alpha=.90 ; 4)$ Healthcare Policy, Finance, Regulation (HCPFR), $\alpha=.77$; 5) Information Management and Application of Patient Technology (IMAPCT), $\alpha=.73 ; 6)$ Inter-professional Communication and Collaboration (IPCC), $\alpha=.78 ; 7)$ Organization and Systems Leadership for Quality and Safety (OSLQS), $\alpha=.85$; and, 8) Professionalism and Professional Values (PPV), $\alpha$ $=.57$. Paired-sample $t$-tests indicated that self-confidence improved on each of the eight ANE generalist nursing practice scales at each time point. These findings are reported in Table 2.

For the Generalized Linear models, there was a significant effect of program time on student's reported self-confidence on each of the eight domains of generalist nursing practice at the $p<.05$ level. That is, all students reported significant increases in their confidence with performing the competencies associated with generalist nursing practice in the high dose simulation clinical teaching model from the program mid-point and end of the program. In the between subject analyses, there was no significant effect of gender or program type on student's perceived self-confidence in performing the eight generalist nursing practice competencies at the $p<$ .05 level. The full model results are reported in Table 3 .

\section{Discussion}

Our study adds to the growing body of evidence to support the use of high fidelity simulation as an effective pedagogy for promoting undergraduate students' confidence in their clinical practice abilities. ${ }^{[29,30]}$ Self-confidence is an important predictor for success in professional roles, job satisfaction, and career longevity, ${ }^{[13,14]}$ all of which have implications for nursing faculty charged with educating new workforce entrants. Our results show that student's perceptions of their confidence in carrying out the eight practice competencies associated with generalist nursing practice set forth by the American Association of Colleges of Nursing, the National League for Nursing, and National Council of State Boards of Nursing significantly improved over time in the undergraduate program. Our results provide evidence that substituting $50 \%$ of the clinical teaching hours in the core medical surgical courses in combination with traditional clinical teaching approaches, is a viable educational innovation to support students' development as confident practitioners. 
The integration of simulation as a clinical teaching method ticularly in acute care settings where the majority of clinical enable faculty to direct the depth, breath, and quality of teaching occurs, high dose simulation teaching models are an course content in a controlled and safe learning environment. emerging option to support the goals of high quality nursing Given the complexity of contemporary nursing practice, par- education.

Table 2. Students' Perceived Self-Confidence in Generalist Nursing Practice at Time 1 and Time 2

\begin{tabular}{|c|c|c|c|c|c|c|}
\hline \multirow{2}{*}{$\begin{array}{l}\text { Assessment of Nursing Education Scale Practice } \\
\text { Competencies }(n=127)\end{array}$} & \multicolumn{2}{|l|}{ Mean } & \multicolumn{2}{|c|}{$\begin{array}{l}\text { Standard } \\
\text { Deviation }\end{array}$} & \multirow{2}{*}{$t$} & \multirow{2}{*}{$\begin{array}{l}\text { Sig. } \\
\text { (2-tailed) }\end{array}$} \\
\hline & Mid & End & Mid & End & & \\
\hline $\begin{array}{l}\text { CPPH - Clinical presentation and population health ( } 3 \\
\text { items) }\end{array}$ & 13.16 & 16.09 & 2.831 & 2.682 & -11.509 & 0.00 \\
\hline EBP- Evidence based practice (6 items) & 26.7 & 31.65 & 5.326 & 4.602 & -11.274 & 0.00 \\
\hline GNP - Generalized nursing practice (12 items) & 50.53 & 62.19 & 11.4 & 10.391 & -12.542 & 0.00 \\
\hline $\begin{array}{l}\text { HCPFR - Health care policy, finance and regulation (4 } \\
\text { items) }\end{array}$ & 16.36 & 20.43 & 4.244 & 3.706 & -11.629 & 0.00 \\
\hline $\begin{array}{l}\text { IMPACT - Information management and application of } \\
\text { patient care technology ( } 4 \text { items) }\end{array}$ & 18.56 & 22.22 & 4.181 & 3.628 & -10.44 & 0.00 \\
\hline $\begin{array}{l}\text { IPCC - Inter-professional communications and } \\
\text { collaboration ( } 4 \text { items) }\end{array}$ & 17.74 & 21.53 & 3.978 & 3.473 & -11.206 & 0.00 \\
\hline $\begin{array}{l}\text { OSLQS - Organization and systems leadership for } \\
\text { quality and safety (7 items) }\end{array}$ & 31.13 & 36.69 & 6.357 & 5.637 & -11.052 & 0.00 \\
\hline PPV - Professionalism and professional values (3 items) & 14.6 & 16.66 & 2.697 & 2.489 & -8.7 & 0.00 \\
\hline
\end{tabular}

Note. ANE uses a seven point Likert scale ranging from $1=$ not at all confident to $7=$ extremely confident.

Table 3. Results for General Linear Model Analysis of Student Confidence Over Time*

\begin{tabular}{|c|c|c|c|c|c|c|c|c|}
\hline & \multicolumn{8}{|c|}{ Nursing Practice Competencies } \\
\hline & СРPH & EBP & GNP & HCPFR & IMAPCT & IPCC & OSLQS & PVV \\
\hline \multicolumn{9}{|l|}{ Predictors } \\
\hline \multicolumn{9}{|l|}{ Test-Retest } \\
\hline Change in self-confidence from & $\mathrm{F}=22.16$ & $\mathrm{~F}=12.26$ & $\mathrm{~F}=13.56$ & $\mathrm{~F}=27.00$ & $\mathrm{~F}=20.33$ & $F=13.64$ & $\mathrm{~F}=21.95$ & $\mathrm{~F}=11.63$ \\
\hline $\begin{array}{l}\mathrm{T} 1 \text { (program mid-point) and } \mathrm{T} 2 \\
\text { (program end point) }\end{array}$ & $p=.000$ & $p=.001$ & $p=.000$ & $p=.000$ & $p=.000$ & $p=.000$ & $p=.000$ & $p=.001$ \\
\hline $\begin{array}{l}\text { Gender } \\
\text { Differences between male and } \\
\text { female students }\end{array}$ & $\mathrm{F}=.003$ & $\mathrm{~F}=.307$ & $\mathrm{~F}=.292$ & $\mathrm{~F}=.353$ & $\mathrm{~F}=.241$ & $\mathrm{~F}=.000$ & $\mathrm{~F}=.332$ & $\mathrm{~F}=.203$ \\
\hline \multicolumn{9}{|l|}{ Program Type } \\
\hline $\begin{array}{l}\text { Differences between traditional } \\
\text { and accelerated second degree } \\
\text { students }\end{array}$ & $\mathrm{F}=.103$ & $\mathrm{~F}=.075$ & $\mathrm{~F}=.305$ & $\mathrm{~F}=.120$ & $\mathrm{~F}=.058$ & $\mathrm{~F}=.217$ & $\mathrm{~F}=.275$ & $\mathrm{~F}=.061$ \\
\hline
\end{tabular}

Note. Breath of Nursing Education Practice Competencies: 1) $\mathrm{CPPH}=\mathrm{Clinical}$ Prevention and Population Health; 2) EBP=Evidence Based Practice; 3) GNP=Generalist Nursing Practice; 4) HCPFR=Healthcare Policy, Finance and Regulation; 5) IMAPCT=Information Management and Application of Patient Technology; 6) IPCC= Inter-professional Communication and Collaboration; 7) OSLQS=Organization and Systems Leadership for Quality and Safety; 8) PVV=Professionalism and Professional Values.

*Significant findings reported in bold type. $(p \leq .05)$

Our study points to a number of new avenues for research on the effectiveness of high-dose simulation clinical teaching models in undergraduate nursing education. First, new studies using random assignment and longitudinal designs are necessary to more fully understand the effects of both highdose simulation and traditional clinical teaching approaches on a range of important educational and practice outcomes such as, academic performance and first time NCLEX pass rates; critical thinking, prioritization and communication skills; knowledge and skill retention and application; and clinical competence in the first year of professional practice. $^{[1]}$ 
Moving beyond the educational period, new studies focused on identifying the influence of simulation dose on new graduates' performance on high-stakes testing used during the job selection process is a logical next step in this line of inquiry. Results from such studies could be used to inform the design of nursing curricula so that new graduates are well prepared for a competitive job market and the contemporary realities of professional nursing practice.

Finally, the Assessment of Nursing Education scale ${ }^{[22]}$ used in this study merits broader use in nursing education research to gauge the depth and breadth of curricular content in undergraduate nursing programs. The ANE could be used to compare high dose simulation clinical teaching models with traditional clinical teaching models to assess the range of competencies that students are exposed to in controlled (i.e.: simulation) and naturalistic (i.e.: traditional) practice environments. Further, the ANE can be used as a self- assessment tool to guide competency development activities for pre-licensure students and novice practitioners during the early years of clinical practice.

\section{Limitations}

The limitations of this study should be considered when interpreting the results.

First, it is important to note that the number of clinical teaching hours spent in in-person or simulated learning activities is not regulated by our State Board of Nursing and the Department of Education. Thus, the market and the regulatory environment were conducive for adopting a high-dose simulation model. Other schools of nursing may not face the same market demands, and thus, a high-dose simulation model may not be a feasible, or an appropriate curricular innovation to adopt. Nonetheless, the results of our study suggest that students are confident about their clinical practice competencies learned in a high-dose simulation clinical teaching model.

The smaller number of students who completed the survey at mid-point and end-point than the sample as a whole is a second limitation of this study. Nonetheless, our study is one of the few employing a longitudinal design to assess changes in students' perceived self-confidence with clinical practice. ${ }^{[3,4,28]}$ Finally, the study findings are not generalized to all nursing students; $80 \%$ of the undergraduate students in the study were enrolled in the accelerated, second-degree program. According to the AACN, at the time we conducted this study there were 233 accelerated BS programs with approximately 13,605 enrolled students. ${ }^{[30]}$ Our program is part of a larger trend in nursing education focused on increasing the supply of registered nurses in a timely and efficient manner. The students in the accelerated and traditional bachelor's degree programs are in the same classroom, and as our results show, there were no significant differences in perceived confidence with performing the tasks associated with generalist nursing practice between the two groups of students, thus improving our confidence in the results.

\section{Conclusion}

This study contributes to the evidence base on the efficacy of high dose simulation teaching models in undergraduate nursing education. We show that student's confidence with carrying out eight core competencies associated with generalist nursing practice set forth by the American Association College of Nursing, the National League for Nursing and the National Council of State Boards of Nursing significantly change over time. Further, there was no significant effect for student gender (male/female) or program type (traditional undergraduate program/ accelerated second degree) on student's self-confidence ratings. Because self-confidence is an important predictor of future career success, we add to the growing body of research that examines the link between different clinical teaching approaches and student's perceptions of their abilities to enact their roles as professional registered nurses.

\section{ACKNOWLEDGEMENTS}

Supported in part by a grant from the Robert Wood Johnson Foundation's Evaluating Innovations in Nursing Education Program Grant \#68172, H. Richardson, DrPH, RN, FAAN, Principal Investigator. L. Goldsamt, PhD and J. Simmons, EdD, National Development and Research Institutes, Inc., Program Evaluators.

The first author was a participant in the 2015 NLN Scholarly Writing Retreat, sponsored by the NLN Chamberlain College of Nursing Center for the Advancement of the Science of Nursing Education.

\section{Conflicts of InTEREST Disclosure}

The authors declare that there is no conflict of interest.

\section{REFERENCES}

[1] Hayden JK, Smiley RA, Gross L. Simulation in nursing education: current regulations and practices. Journal of Nursing Regulation. 2014 Jul; 5(2): 25-30. http://dx.doi.org/10.1016/S2155-8

Published by Sciedu Press
$256(15) 30084-3$

[2] Nehring WN, Lashley FR. Nursing Simulation: A review of the past 40 years. Simulation Gaming. 2009 Aug; 40(4): 528-552. 
http://dx.doi.org/10.1177/1046878109332282

[3] Richardson H, Gilmartin MJ, Fulmer T. Shifting the clinical teaching paradigm in undergraduate nursing education to address the nursing faculty shortage. Journal of Nursing Education. 2012 Apr; 51(4) 226-231. PMid:22320176. http://dx.doi.org/10.3928/01484 834-20120210-04

[4] Weaver A. High-fidelity patient simulation in nursing education: an integrative review. Nursing Education Perspectives. $2011 \mathrm{Jan}-\mathrm{Feb}$; 32(1): 37-40. PMid:21473481. http://dx.doi.org/10.5480/1 536-5026-32.1.37

[5] Shinnick MA, Woo MA, Mentes JC. Human patient simulation: state of the science in pre-licensure nursing education. Journal of Nursing Education. 2011 Feb; 50(2): 65-72. PMid:21210612. http://dx.doi.org/10.3928/01484834-20101230-01

[6] Lapkin S, Levett-Jones T, Bellchambers H, et al. Effectiveness of patient simulation manikins in teaching clinical reasoning skills to undergraduate nursing students: a systematic review. Clinical Simulation in Nursing. 2010 Nov-Dec; 6(6): e207-e222. http: //dx.doi.org/10.1016/j.ecns.2010.05.005

[7] Alinier G, Hunt WB, Gordon R. Determining the value of simulation in nurse education: study design and initial results. Nurse education in practice. $2004 \mathrm{Sep}$ 4(3): 200-207. http://dx. doi .org/10.10 16/S1471-5953(03) 00066-0

[8] Radhakrishnan K, Roche JP, Cunningham H. Measuring clinical practice parameters with human patient simulation: a pilot study. International Journal of Nursing Education Scholarship. 2007 Feb; 4(1).

[9] Howard VM. A comparison of educational strategies for the acquisition of medical-surgical nursing knowledge and critical thinking skills: human patient simulator vs. the interactive case study approach [dissertation]. [Pittsburgh, PA]: University of Pittsburgh; 2007.

[10] Lang CS, Hahn JA. BLAST model: An innovative approach to prepare second-degree accelerated BSN students for inpatient psychiatric clinical experiences. Journal of Psychosocial Nursing \& Mental Health Services. 2013 Mar; 51(3): 38-45.

[11] Ravert P. Patient simulator sessions and critical thinking. Journal of Nursing Education. 2008 Dec; 47(12): 557-562. PMid:19112746. http://dx.doi.org/10.3928/01484834-20081201-06

[12] Spence Laschinger HK. Effect of empowerment on professional practice environments, work satisfaction, and patient care quality: further testing the Nursing Worklife Model. Journal of Nursing Care Quality. 2008 Oct-Nov; 23(4): 322-330. PMid:18431259. http: //dx.doi.org/10.1097/01.NCQ.0000318028.67910.6b

[13] Judge T, Erez A, Bono J. The power of being positive: the relationship between positive self-concept and job performance. Human Performance. 1998; 11(2-3): 167-187. http://dx.doi.org/10 1080/08959285.1998.9668030

[14] Stakjovic AD, Luthans F. Self-efficacy and work-related performance: a meta-analysis. Psychological Bulletin. 1998; 124(2): 240-261. http://dx.doi.org/10.1037/0033-2909.124.2.240

[15] Fisher D, King L. An integrative literature review on preparing nursing students through simulation to recognize and respond to the deteriorating patient. Journal of Advanced Nursing. 2013 Nov; 69(11): 2375-88. PMid:23734570.

[16] Benner P. Educating Nurses: A Call for Radical Transformation. New York: Carnegie Foundation; 2009.
[17] Leigh GT. High-fidelity patient simulation and nursing students' selfefficacy: a review of the literature. International Journal of Nursing Education Scholarship. 2008 Sep; 5(1): 1-17.

[18] Valizadeh L, Amini A, Fathi-Azar E, et al. The effect of simulation teaching on baccalaureate nursing students' self-confidence related to peripheral venous catheterization in children: A randomized trial. Journal of Caring Sciences. 2013 Jun; 2(2): 157-164. PMid:25276722.

[19] Cooper S, Kinsman L, Buykx P, et al. Managing the deteriorating patient in a simulated environment: nursing students' knowledge, skill and situation awareness. Journal of Clinical Nursing. 2010 Aug; 19(15-16): 2309-18. PMid:20659205. http://dx.doi.org /10.1111/j.1365-2702.2009.03164.x

[20] Blum C, Borglund S, Parcells D. High fidelity nursing simulation: impact on student self confidence and clinical competence. International Journal of Nursing Education and Scholarship. 2010 June; 7(1): 1548-1553.

[21] Richardson H, Goldsamt LA, Simmons J, et al. Increasing faculty capacity: Findings from an evaluation of simulation clinical teaching. Nursing Education Perspectives. 2014 Sep-Oct; 35(5): 308-314. PMid:25291926. http://dx.doi.org/10.5480/14-1384

[22] Evaluating Innovations in Nursing Education tools: student selfassessment of the breadth of nursing education. Robert Wood Johnson Foundation [Internet]. c 2009 [cited year mo day]. Available from: http://64.130.38.139/research-findings-tools/

[23] Bandura A. Guide for creating self-efficacy scales. In Pajares F and Urdan T. (Eds.). Self-efficacy beliefs of adolescents. Greenwich, CT: Information Age Publishing; 2006.

[24] American Association of Colleges of Nursing. The essentials of baccalaureate education for professional nursing practice. Washington, D.C.: American Association of Colleges of Nursing; 2008.

[25] National League for Nursing. Outcomes and competencies for graduates of practical/vocational, diploma, baccalaureate, master's and research doctorate programs in nursing. New York, NY: National League for Nursing; 2012.

[26] National Council of State Boards of Nursing. 2011 RN practice analysis: linking the NCLEX-RN(C) examination to practice. NCSBN Research Brief. 2012 Jan; 53: 1-177.

[27] IBM Corp. IBM SPSS statistics for Windows, version 22.0. Armonk, NY: IBM Corp; released 2013.

[28] American Association of Colleges of Nursing. Race/ethnicity data of students enrolled in nursing programs: 10-year data on minority students in baccalaureate and graduate programs. Washington, D.C.: American Association of Colleges of Nursing; 2015. [cited 2015 Aug 5]. Available from: http://www.aacn.nche.edu/research-d ata/EthnicityTbl.pdf

[29] Yuan HB, Williams BA, Fang JB. The contribution of high fidelity simulation to nursing student's confidence and competence: a systematic review. International Nursing Review. 2012 Mar; 59(1): 26-33. http://dx.doi.org/10.1111/j.1466-7657.2011.00964.x

[30] Dunn KE, Osborne C, Link HJ. High-fidelity simulation and nursing student self-efficacy: does training help the little engines know they can? Nursing Education Perspectives. 2014 Nov; 35(6): 403-414. http://dx.doi.org/10.5480/12-1041.1 